\title{
FLOOD-PULSE AND RIVERSCAPE DYNAMICS IN A BRAIDED GLACIAL RIVER
}

\author{
Florian Malard, ${ }^{1,4}$ Urs Uehlinger, ${ }^{2}$ Rainer ZaH, ${ }^{3}$ And Klement TocKner ${ }^{2}$ \\ ${ }^{1}$ UMR CNRS 5023, Ecologie des Hydrosystemes Fluviaux, Universite Claude Bernard Lyon, 43 Bd 11 Novembre 1918, \\ 69622 Villeurbanne, France \\ ${ }^{2}$ Department of Limnology, EAWAG/ETH, Ueberlandstrasse 133, 8600 Duebendorf, Switzerland \\ ${ }^{3}$ EMPA, Sustainable Information Technology, Lerchenfeldstrasse 5, 9014 St. Gallen, Switzerland
}

\begin{abstract}
River ecosystems are increasingly viewed as dynamic riverscapes; their extent, composition, and configuratio vary in response to the pulsing of discharge. Although compositional and configurationa shifts in riverscapes are thought to control ecosystem processes and biodiversity, attempts to quantify riverscape dynamics of braided rivers are scarce. We measured monthly changes in the length, spatial arrangement, and age distribution of clear (groundwater-fed) and turbid-water (glacial-fed) channels during two annual cycles in a braided glacial river. Biological data from concurrent studies were used to assess the effects of seasonal changes in the size and pattern of the riverscape on local zoobenthic density, standing crop of epilithic algae, and spatiotemporal distribution of the hyporheos. The hydrological processes involved in the expansion-contraction cycle of the riverscape resulted in a complex, albeit predictable, pattern of change in the proportion and spatial arrangement of clear and turbid channels. On average, $30 \%$ of the riverscape was renewed at monthly intervals. Surface hydrological connectivity and the length of turbid channels increased logarithmically with increasing discharge. The length of clear channels increased up to a threshold discharge of $1.5 \mathrm{~m}^{3} / \mathrm{s}$, above which surface floodin resulted in the contraction and fragmentation of clear water bodies. Turbid channels exhibited a unimodal age distribution, whereas clear channels had two cohorts that appeared during the expansion and contraction phases. The renewal pattern and configuratio of the riverscape changed little between years despite differences in discharge and the occurrence of several rainfallinduced spates. The density of benthic invertebrate communities in the main channel decreased with increasing size of aquatic habitats indicating that local zoobenthic density was affected by dilution-concentration effects. The disproportionate increase in the proportion of glacial-fed habitats during summer high flow limited the standing crop of epilithic algae in this braided river. The spatial arrangement of inhospitable glacial-fed habitats probably impeded the colonization of newly created suitable habitats by invertebrates with poor dispersal capacities. Quantificatio of riverscape dynamics is critical to understanding how changes in size, composition, and configuratio of braided rivers affect biodiversity, bioproduction, and ecosystem processes.
\end{abstract}

Key words algae; benthos; expansion-contraction cycle; floo pulse; glacial water; groundwater; habitat life span; hyporheos; inundation; shifting mosaic; spatial heterogeneity; wetland.

\section{INTRODUCTION}

River ecosystems are increasingly viewed as dynamic riverscapes (i.e., spatially and temporally heterogeneous areas made of connected water bodies), their extent, composition, and configuratio vary over several temporal scales (Malard et al. 2000, Fausch et al. 2002, Ward et al. 2002; Stanford et al., in press). Temporal variation in the discharge of multiple water sources (i.e., river water, direct precipitation, groundwater, and local runoff) not only controls the spatial extent of the riverscape but also modifie the relative areas and spatial arrangement of water bodies, each having distinct hydraulic attributes (e.g., lentic vs. lotic), water

Manuscript received 27 May 2004; revised 31 August 2005; accepted 2 September 2005. Corresponding Editor: C. R. Hupp.

${ }^{4}$ E-mail: malard@univ-lyon1.fr temperatures, and nutrient concentrations. Although compositional and configurationa shifts in the riverscape are thought to control ecosystem processes and biodiversity (Junk et al. 1989, Benke et al. 2000, Tockner et al. 2000, Robinson et al. 2002), these relationships are still poorly understood. In river-floodplai systems characterized by nonerosive discharge pulses, the proportional area and spatial arrangement of water bodies fed by different water sources are expected to change in a predictable way as discharge increases (inundation sequence) and decreases (recession sequence) (Lesack and Melack 1995, Tockner et al. 2000). In contrast, changes in the composition and configuratio of the riverscape are difficul to predict in braided gravel-bed rivers characterized by frequent erosive flood that continuously reshape their morphology (Arscott et al. 2002, Van der Nat et al. 2003). 

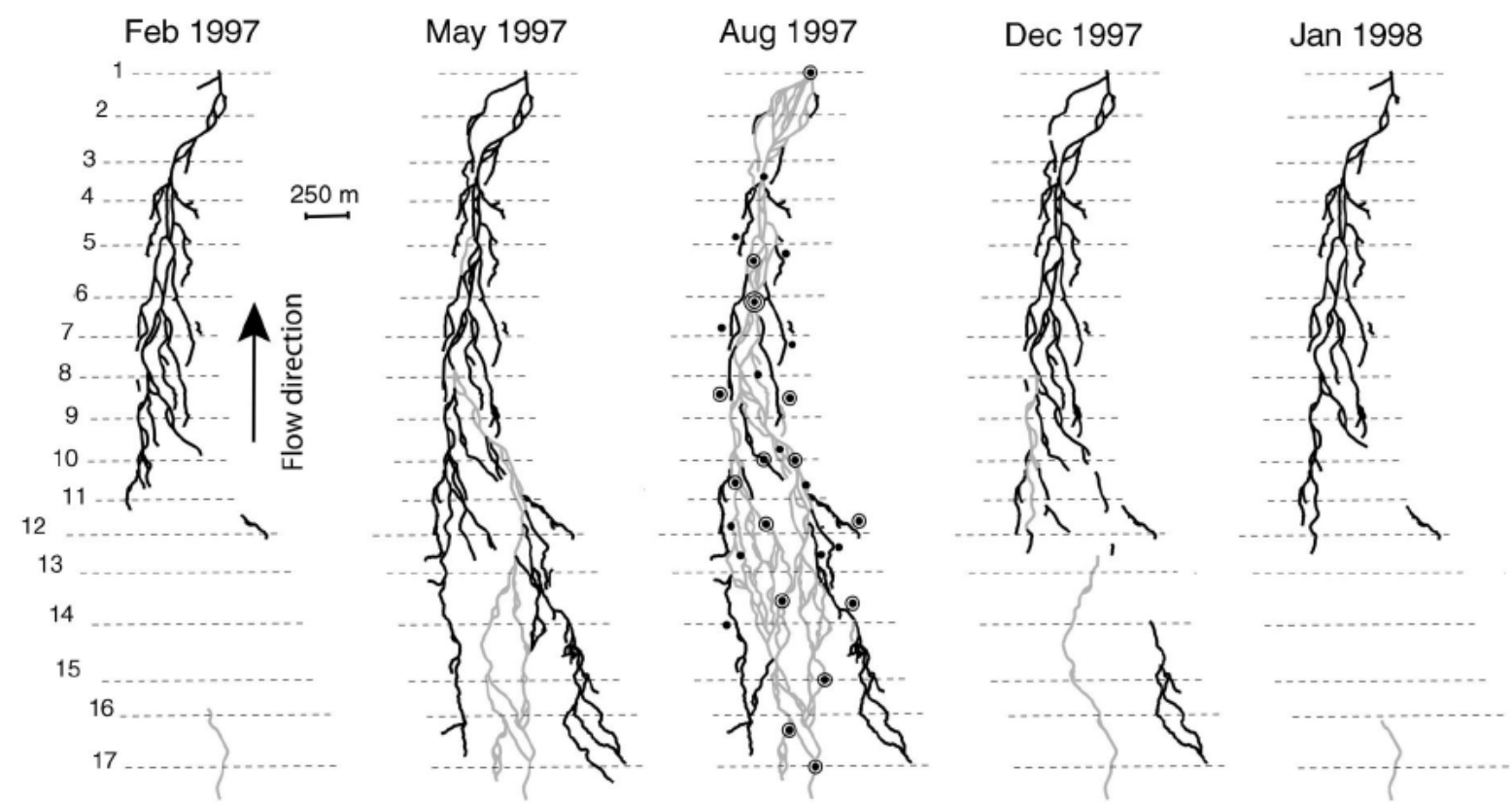

FIG. 1. Expansion-contraction cycle of the channel network in 1997 showing the distribution of clear channels (black lines) and turbid channels (gray lines) for selected months. Dashed lines indicate the sampling transects (numbers along left of figure). Solid circles with two, one, and no rings correspond to sampling sites of the zoobenthos, periphyton, and hyporheos.

Braided glacial rivers exhibit a highly predictable annual flow pulse caused by the freeze-thaw cycle onto which summer diel discharge fluctuations and unpredictable spates induced by rainfall are superimposed (Röthlisberger and Lang 1987). Glaciers and subsurface aquifers are the main water sources that interact over time and space to produce a dynamic riverscape made of contrasting glacial water fed channels and groundwater-fed channels (Brown et al. 2003). Groundwater-fed channels are more suitable habitats for algae and invertebrates than are glacial-fed channels because they have distinctly lower turbidity and shear stress, and higher temperatures and DOC concentrations (Ward 1994, Milner et al. 2001, Tockner et al. 2002, Burgherr et al. 2002, Bürgi et al. 2003, Uehlinger et al. 2003). Understanding riverscape dynamics is of particular importance because the relative proportion, life span, and spatial arrangement of these contrasting water bodies control biodiversity and bioproduction within the braided band.

The main objectives of this paper are to quantify the seasonal dynamics in the extent, composition, and configuration of a headwater glacial riverscape during two annual cycles; and to assess the effects of seasonal changes in the size and pattern of the riverscape on local zoobenthic density, standing crop of epilithic algae, and spatiotemporal distribution of the hyporheos. We hypothesized that seasonal expansion-contraction cycles would result in a predictable trend of change in area, spatial arrangement, and life span of glacial-fed and groundwater-fed habitats. Seasonal changes in aquatic habitat size were expected to produce concom- itant variation of zoobenthic density in the main channel. We also expected that the rising proportion of glacial-fed habitats during high summer flows would limit primary production and impede the dispersal of noninsect taxa within the riverscape.

\section{Study Site}

The Roseg River, Switzerland, is a steep-gradient (1.9-4.8\%), braided gravel-bed river. Its geomorphology, hydrology, and ecology have been investigated in exceptional detail (Ward and Uehlinger 2003). The catchment area is $66.5 \mathrm{~km}^{2}, 30 \%$ of which is covered by glaciers and $40 \%$ of which is bare rock or glacial till without vegetation. The braided band (elevation 1981-2055 m above sea level) begins $1.3 \mathrm{~km}$ downstream from a glacier terminus and covers a distance of $2.6 \mathrm{~km}$ (total area, $0.67 \mathrm{~km}^{2}$ ). Morphologically, two sections can be distinguished: an upper band up to 510 $\mathrm{m}$ wide (transects 11 to 17 in Fig. 1) and a lower band between 130 and $260 \mathrm{~m}$ in width (transects 1 to 11 in Fig. 1). The river has a distinct seasonal flow regime: daily mean discharge peaks during the ice-melt season (from 6 to $10 \mathrm{~m}^{3} / \mathrm{s}$ in July and August) and is lowest in winter (approximately $0.2 \mathrm{~m}^{3} / \mathrm{s}$ from January to March) when surface flow is sustained solely by groundwater.

\section{MethodS}

\section{Mapping of the channel network}

Aerial photographs of the braided band were taken on 5 August 1997 with a hand-held 35-mm camera from 
a helicopter (at an altitude of $580 \mathrm{~m}$ above the ground) and on 23 June 1999 with a standard aerial camera with color infrared fil (WILD 21 NAGIIA-F, focal length $214.74 \mathrm{~mm}$; Leica Geosystems, St. Gallen, Switzerland) from an airplane (altitude, $1181 \mathrm{~m}$ above the ground). Additional aerial images taken in summer 1998 , in combination with ground control points, were used for the generation of a digital elevation model (DEM) at a precision $<0.15 \mathrm{~m}$ (Zah et al. 2000). The high-accuracy DEM and color-IR orthophotos from 1998 were used for the spatial correction of images taken in 1997 and 1999. Spatial corrections were performed using OrthoEngine (by PCI-Geomatics, Richmond Hill, Ontario, Canada) on an UNIX-workstation. Using ArcInfo (ESRI 1994), the flo paths of the channels with surface flo in summer 1997 and 1999 (i.e., maximum extent of the channel network) were digitized as line coverages. The channel network coverage consisted of 586 and 922 channel segments in 1997 and 1999, respectively.

\section{Turbidity measurements and monthly mapping of the riverscape}

In 1997 and 1999, changes in the pattern of channels with surface flo and water turbidity (nephelometric turbidity units, NTU) were recorded on fiel surveys carried out at monthly intervals (total, 24 surveys). Mean annual discharge was lower in $1997\left(2.95 \mathrm{~m}^{3} / \mathrm{s}\right)$ than in $1998\left(3.31 \mathrm{~m}^{3} / \mathrm{s}\right)$ and $1999\left(3.55 \mathrm{~m}^{3} / \mathrm{s}\right)$. Moreover, the river was affected by a series of rain-induced spates between 1997 and 1999 (see Fig. 3). Six spates had a recurrence interval of $>2.5 \mathrm{yr}$ (i.e., instantaneous peak discharge $>27 \mathrm{~m}^{3} / \mathrm{s}$ ). Each month, the presence or absence of water and water turbidity (Cosmos, turbidity meter, Fa. Züllig, Rheineck, Switzerland) were recorded in each channel along 17 perpendicular transects within the braided band (Fig. 1). The number of turbidity measurements for a particular survey varied from 27 to 155 depending on the number of channels with surface flo along each transect $(n=988$ and 1314 measurements in 1997 and 1999, respectively). Results of the monthly fiel surveys were used to map the network of channels with surface flo and the distribution of turbidity. Dry channel segments were excluded from the channel network coverage in ArcInfo and a single turbidity measurement was attributed to each channel segment with surface flo . A threshold turbidity value of 9 NTU was used to map the distribution of groundwater-fed channels (hereafter referred to as clear channels, turbidity $<9$ NTU) and glacialfed channels (hereafter referred to as turbid channels, turbidity $\geq 9$ NTU). This threshold value was selected because turbidity in the main channel and side channels connected upstream with the main glacial channel was always $>9$ NTU during the ice-melt season (Malard et al. 1999,2000$)$. Low temperature $\left(<5^{\circ} \mathrm{C}\right)$, high flo velocity $(>0.5 \mathrm{~m} / \mathrm{s})$, and elevated turbidity ( $>60 \mathrm{NTU})$ prevailing in the main channel and upstream connected channels fed essentially by surface glacial water severely constrained bioproduction and organic matter processing (Robinson et al. 2000, Burgherr et al. 2002, Uehlinger and Zah 2003). Bioproduction hotspots in this braided glacial river corresponded to channels with no upstream connection with the main channel (i.e., downstream connected channels), which were fed either by hillslope or alluvial groundwater.

\section{Sampling of zoobenthos, periphyton, and hyporheos}

A full description of methods used for sampling the zoobenthos, periphyton, and hyporheos was provided by Burgherr et al. (2002), Uehlinger and Zah (2003), and Malard et al. (2003), respectively. Zoobenthic density was measured by collecting three Hess samples $\left(0.043 \mathrm{~m}^{2}\right.$ in area) from randomly selected riffle-ru habitats at a main channel site in April, June, August, October, November, and December 1997 (Fig. 1).

Periphyton biomass was measured at 16 channel sites during three low-flo periods (15 April, 10 November, and 15 December 1997; $Q=0.49 \pm 0.27 \mathrm{~m}^{3} / \mathrm{s}$ [mean $\pm \mathrm{SD}]$ ) and three high-flo periods (5 August, 1 and 29 September 1997; $Q=6.74 \pm 3.80 \mathrm{~m}^{3} / \mathrm{s}$; Fig. 1$)$. At each site and date, fiv to 11 rocks (3-12 cm in width) were sampled at random within a $20 \mathrm{~m}$ long reach. Length, width, and height of the stones were measured with calipers. Filaments of the chrysophyte Hydrurus foetidus were removed with a knife and nonfilamentou algae were scrubbed with a wire brush in a container with water. Aliquots of this periphyton suspension were filtere onto glass fibe filter (Whatman GF/F). Ashfree dry mass of periphyton (AFDM, $\mathrm{g} / \mathrm{m}^{2}$ ) was determined according to Clesceri et al. (1998) and was standardized on half the surface area of the stones. Surface areas of the stones were calculated according to Graham et al. (1988).

Sampling of the hyporheos was carried out at 28 channel sites during the expansion phase (2-6 June 1997; $Q=3.78 \pm 0.51 \mathrm{~m}^{3} / \mathrm{s}$ ), the maximum expansion phase ( 28 July-2 August, $Q=7.85 \pm 0.49 \mathrm{~m}^{3} / \mathrm{s}$ ), the contraction phase (22-27 September, $Q=3.19 \pm 0.13$ $\mathrm{m}^{3} / \mathrm{s}$ ), and one week prior to the drying of most channels in the upper part of the braided band (10-14 November, $Q=0.65 \pm 0.10 \mathrm{~m}^{3} / \mathrm{s}$; Fig. 1). Hyporheic samples were collected by driving a mobile pipe $(0.025$ $\mathrm{m}$ internal diameter with $0.005-\mathrm{m}$ holes at the base) to a depth of $30 \mathrm{~cm}$ below the streambed. Ten liters of interstitial water and sediment were immediately extracted using a Bou-Rouch pump (Bou and Rouch 1967). Zoobenthic and hyporheic samples were filtere through a $100-\mu \mathrm{m}$ mesh net and preserved in $4 \%$ formaldehyde. In the laboratory, invertebrates were sorted, counted, and identifie to the lowest practical taxonomic level using a dissecting microscope.

\section{Data analysis}

Extent and composition of the riverscape.-Wexamined changes in the length of the total channel net- 
work, turbid channels, and clear channels and surface hydrological connectivity as a function of river discharge. Surface hydrological connectivity was define as the percentage of the total channel length having an upstream surface connection with the main channel.

Relative change of the riverscape. - $\mathrm{d}$ quantify changes in the riverscape between two consecutive months, channels were placed into eight categories: 1 , clear channels that stayed clear channels; 2, turbid channels that stayed turbid channels; 3 , dry channels that became clear channels; 4 , dry channels that became turbid channels; 5 , clear channels that became turbid channels; 6, turbid channels that went dry; 7, turbid channels that became clear channels; and $i_{8}$, clear channels that went dry. The relative change in the riverscape was define as the percentage of the total channel network length that was modifie between two consecutive months, and was calculated as follows:

$$
\text { relative change }=\frac{\sum_{i=3}^{N=8} L_{i}}{\sum_{i=1}^{N=8} L_{i}}
$$

where $L_{i}=$ length of channels in category $i$.

Temporal changes in the fragmentation of clear channels were assessed by measuring their patchiness (PA) define as the number of clear patches divided by the total length of clear channels. A clear patch was define as a group of contiguous channels carrying clear water.

Life span distribution of channels.-Monthlyhanges in the life span distribution of clear and turbid channels were examined by attributing a life span to each channel segment. The life span of a channel segment was define as the continuous time this segment carried either clear or turbid water. Segment life span was reset to zero each time that a channel segment went dry. For example, the life span of a clear segment flowin from May to September was 1, 2, 3, 4, and 5 mo in May, June, August, and September, respectively. If this channel segment went dry or became fed by turbid water in July, its life span was 1, 2, 1, and 2 mo in May, June, August, and September, respectively.

Functional classificatio of habitats.-Basedn this detailed analysis of riverscape dynamics, we developed a functional classificatio of aquatic habitats. The duration of the aquatic phase and duration of clear water flo were used to distinguish between fiv habitats: I, permanent habitats fed exclusively by clear water; II, permanent habitats fed by clear water in winter and by turbid water during the ice-melt season; III, temporary habitats fed exclusively by clear water; IV, temporary habitats fed by clear water in spring and/or autumn and by turbid water in summer; and V, temporary habitats fed exclusively by turbid water.

Zoobenthic density, periphyton biomass, and distribution of the hyporheos.-W examined the relationship between zoobenthic density at the main channel site and total aquatic area using linear and nonlinear functions. Channel areas with surface flo in summer 1997 (i.e., maximum area of the channel network) were digitized as a polygon coverage. Then, seasonal variations in the total aquatic area were obtained by modifying the area of polygons each month using discharge-channel-width relationships measured in multiple channels (data from Burgherr 2000).

Measurements of periphyton biomass at 16 channel sites were used to estimate the standing crop of epilithic algae in the braided band during periods of low and high flo $(n=3$ dates per period). At each date, main channel segments, upstream connected channels, and clear water channels were assigned an average biomass value for each channel type $(4 \leq n \leq 7$ sampling sites per channel type). The standing crop of epilithic algae was then obtained for each date by multiplying the area covered by each channel type by their respective average biomass values.

We tested the relevance of our functional habitat classificatio for explaining spatial variation in the density of two taxonomic groups differing in their dispersal capacities. Repeated-measures analysis of variances was used to test for differences in the density of Chironomidae and Oligochaetes among habitats. The design was a two (habitat effect) by four (date) analysis of variance. The sampling date was introduced as a repeated measures factor in the analysis and its statistical significanc was tested using Wilks' lambda multivariate test. Post hoc Tukey's hsd tests were performed to determine pairwise differences among habitats.

\section{RESUlTS}

\section{Seasonal changes in the extent and composition of the riverscape}

The riverscape exhibited a distinct expansion/contraction cycle in response to the annual pulse in river discharge (Fig. 1). Total channel length and the length of turbid channels increased logarithmically with river discharge (Fig. 2A). Surface hydrological connectivity (SC) followed a similar pattern $(\mathrm{SC}=0.11 \times \ln (Q)$ $\left.+0.35 ; r^{2}=0.86, n=24\right)$. About $60 \%$ of the channel network length became connected upstream with the main channel when river discharge exceeded $5.5 \mathrm{~m}^{3} / \mathrm{s}$. The relationship between length of clear channels and discharge was best explained with a discontinuous logarithmic function (Fig. 2B). The length of clear channels increased with river discharge up to a threshold of $1.5 \mathrm{~m}^{3} / \mathrm{s}$, above which the extent of clear channels decreased again.

\section{Relative change of the riverscape}

The annual pulsing of river discharge resulted in a complex renewal of the channel mosaic (Fig. 3). The relative change between two consecutive months averaged $30 \%$ and $38 \%$ in 1997 and 1999, respectively, 

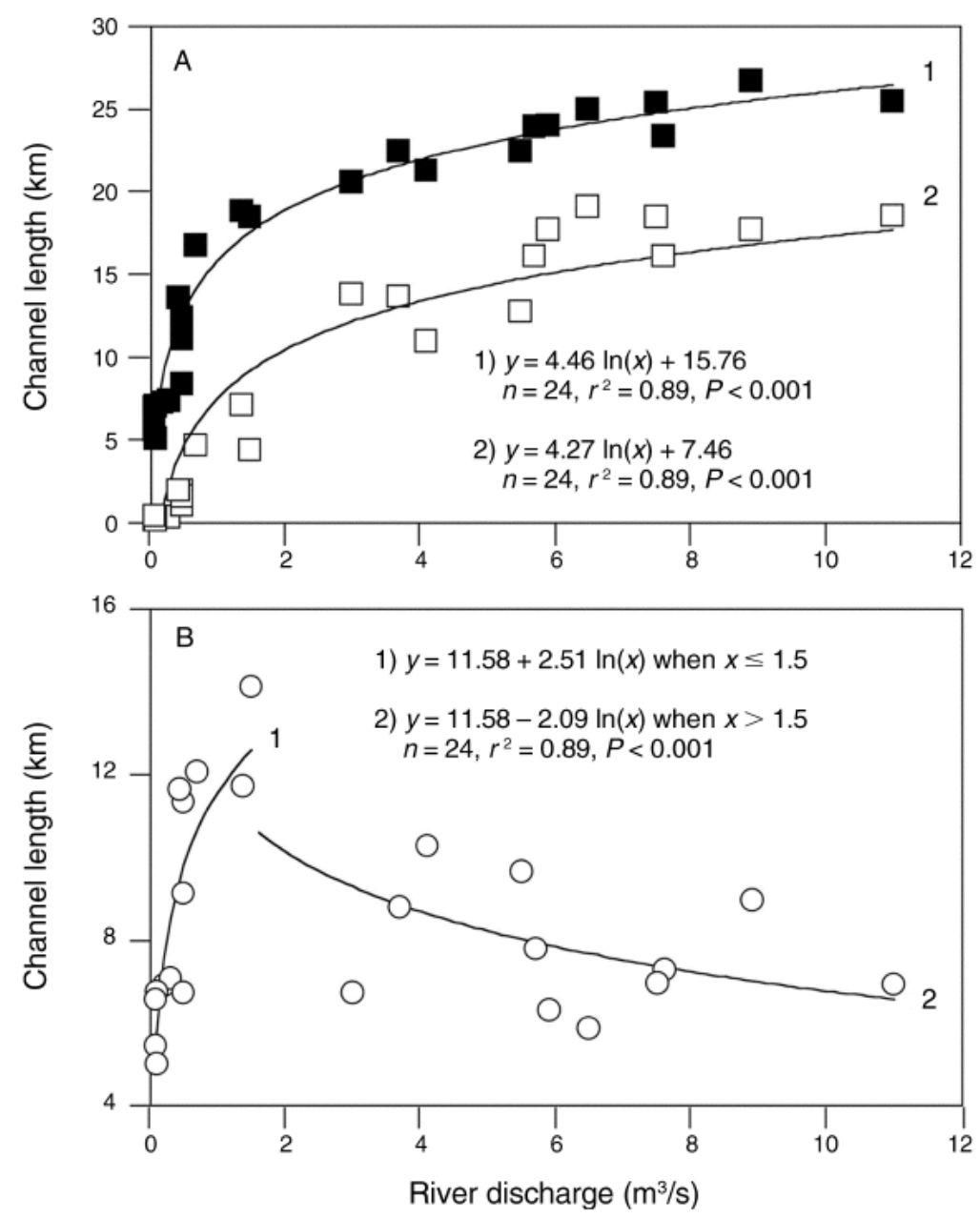

FIG. 2. (A) Relationships between the total length of the channel network (solid squares, line 1) and river discharge and the length of turbid channels (open squares, line 2) and river discharge (data from 1997 and 1999, $n=24$ ). (B) Relationships between the total length of the clear-water channels (open circles) and river discharge. A discontinuous logarithmic function was used to fit this relationship. The length of clear-water channels increased with river discharge up to a threshold of 1.5 $\mathrm{m}^{3} / \mathrm{s}$ (line 1) and decreased above a discharge of $1.5 \mathrm{~m}^{3} / \mathrm{s}$ (line 2 ).

and was markedly higher during the expansion and contraction phases (April-June, 41\%; October-January, $41 \%$ ) than during the phases of minimum and maximum extension of the channel network (FebruaryMarch, 2\%; July-September, $12 \%$ ). Changes in the composition and configuration of the mosaic of clear and turbid channels operated in a specific order as river discharge increased and decreased (Fig. 3). Increase in river discharge resulted in the successive appearance of new clear channels, flooding of dry channels with turbid water, and flushing of clear channels with turbid water. During the recession of flow, some turbid channels began to dry while others became clear channels. Finally, some clear channels went dry. The patchiness (PA) of clear channels increased logarithmically with river discharge $\left(\mathrm{PA}=0.49 \times \ln (Q)+1.55, r^{2}=0.71\right.$, $n=24)$. Whereas clear channels were aggregated in the lower part of the braided band during base flow, flooding resulted in the isolation of many small clear patches along the band margin (Fig. 1).

\section{Life span distribution of clear and turbid water channels}

Turbid channels exhibited a unimodal life span distribution (Fig. 4). The flood pulse resulted in a single cohort of turbid channels that appeared in June and then fell dry or became clear channels during the contraction phase (November). The life span distribution of clear channels was bimodal and more complex than turbid channels. The first cohort of clear channels appeared during the expansion phase (April), whereas the second began during the contraction phase (November). About $9 \mathrm{~km}$ of clear channels were produced in April and May. However, about half of these clear channels persisted for only one or two months before they became turbid channels. The remaining clear channels 

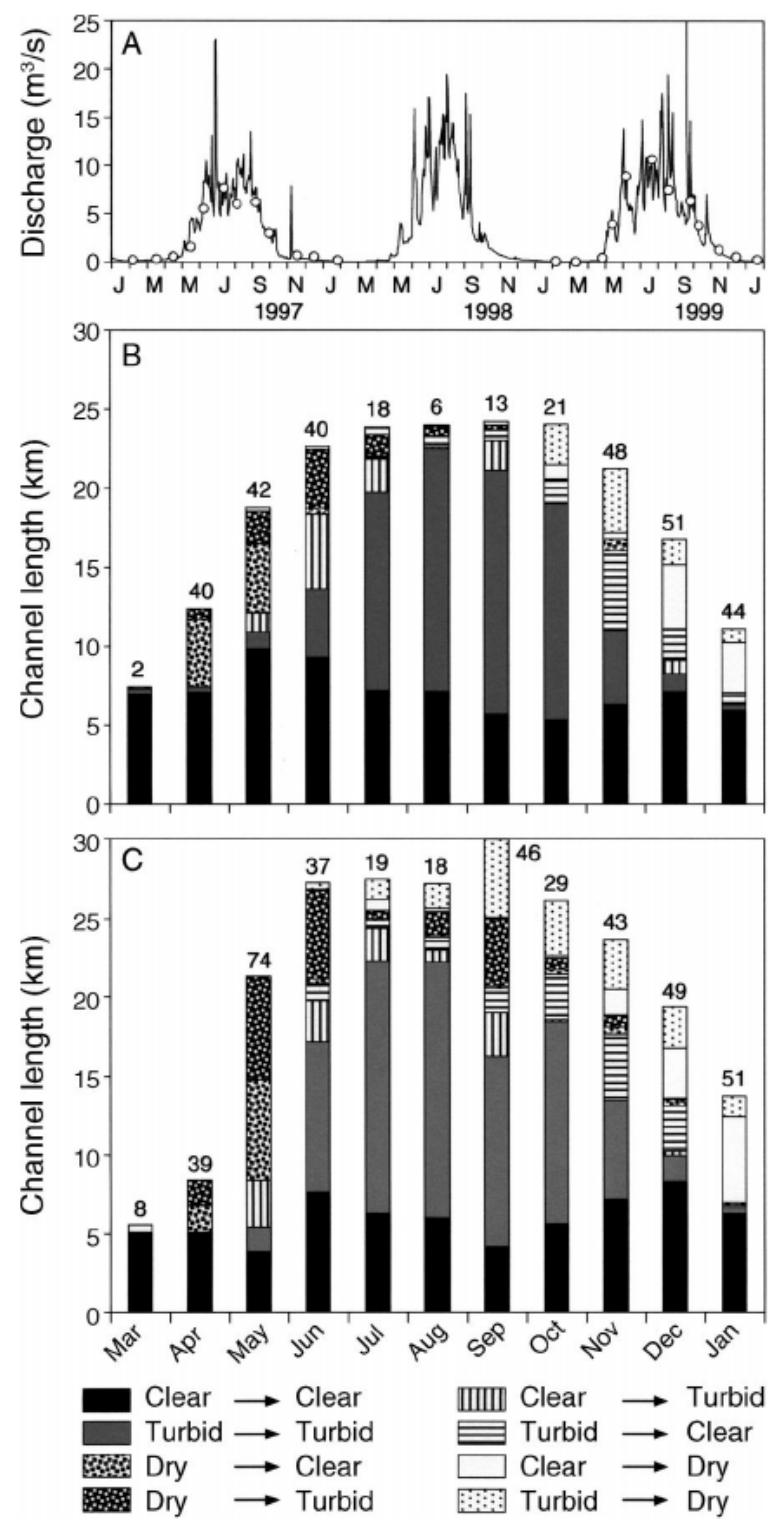

FIG. 3. (A) Daily discharge of the Roseg River in 1997, 1998, and 1999 (open circles indicate the sampling surveys) and changes in the composition of the riverscape between two consecutive months in (B) 1997 and (C) 1999. Numbers at the top of each bar indicate the relative change (\%) of the riverscape between two consecutive months.

remained clear until they went dry during the contraction phase (December). Similarly, about $60 \%$ of the 8 $\mathrm{km}$ of clear channels created during the contraction phase (November and December) went dry within the following two months. The remaining clear channels persisted throughout the winter until they became turbid channels in the next expansion phase (May and June). There were no differences in the seasonal pattern of life span distribution of clear and turbid channels between years 1997 and 1999.

\section{Functional classification of aquatic habitats}

Permanent habitats (types I and II) represented only $27 \%$ and $17 \%$ of the maximum length of the channel network in 1997 and 1999, respectively (Table 1). Permanent habitats fed exclusively by clear water (type I) had a cumulative length of only about $2 \mathrm{~km}$, and represented $<10 \%$ of the maximum length of the channel network. Temporary habitats III, IV, and V had similar flow duration (i.e., from 6 to $7 \mathrm{mo}$ ) but carried clear water for 7,3 , and $0 \mathrm{mo}$, respectively. The relative proportion of habitat types I, II, and III was lower in 1999 than in 1997, whereas that of types IV and V increased.

Habitat mapping revealed that specific habitat types were distributed distinctly along the longitudinal and lateral dimensions of the braided band (Fig. 5). Permanent habitats (types I and II) were mostly restricted to the lower part of the braided band. Type I was located along band margins and type II in the central part of the band. Most temporary habitats were located in the upper part of the braided band. Type III was located at the margins of the upper band, type IV occurred in the center of the upper band between transects 9 and 13 , whereas type $\mathrm{V}$ occupied the center and uppermost part of the band (i.e., between transects 13 to 17). There were few differences in the distribution pattern of habitat types between years. However, habitat type IV extended to the upstream end of the lower band (i.e., between transects 6 and 10) as well as to the right margin in the upper band (i.e., between transects 10 and 14) in 1999.

\section{Ecological effects of changes in system size and spatial pattern}

The relationship between zoobenthic density at the main channel site and total aquatic area was best explained using a power function (Fig. 6). Differences in the aquatic area among sampling dates explained $94 \%$ of the variation in zoobenthic density.

The biomass of epilithic algae was about three to eight times lower in the main channel and upstream connected channels fed by turbid water than in clear channels during high flow periods (ANOVA, channel type effect, $P<0.001$; Tukey test, $P<0.01$; Fig. 7). Our estimates indicated that the standing crop of epilithic algae in the braided band was higher during highflow periods than during low-flow periods, but the difference was not statistically significant ( $t$ test, $P=$ 0.056 ). The total periphyton biomass increased in average only twofold during high flow periods despite a threefold increase in the aquatic area.

Chironomid larvae were more abundant in hyporheic sediments of both permanent and temporary habitats fed exclusively by clear water (I and III) than in glacialfed habitats (II, IV, and V) (ANOVA, habitat effect, $P$ $<0.001$; Tukey tests, $P<0.03$; Fig. 8 ). There were no differences in density between permanent (I) and 


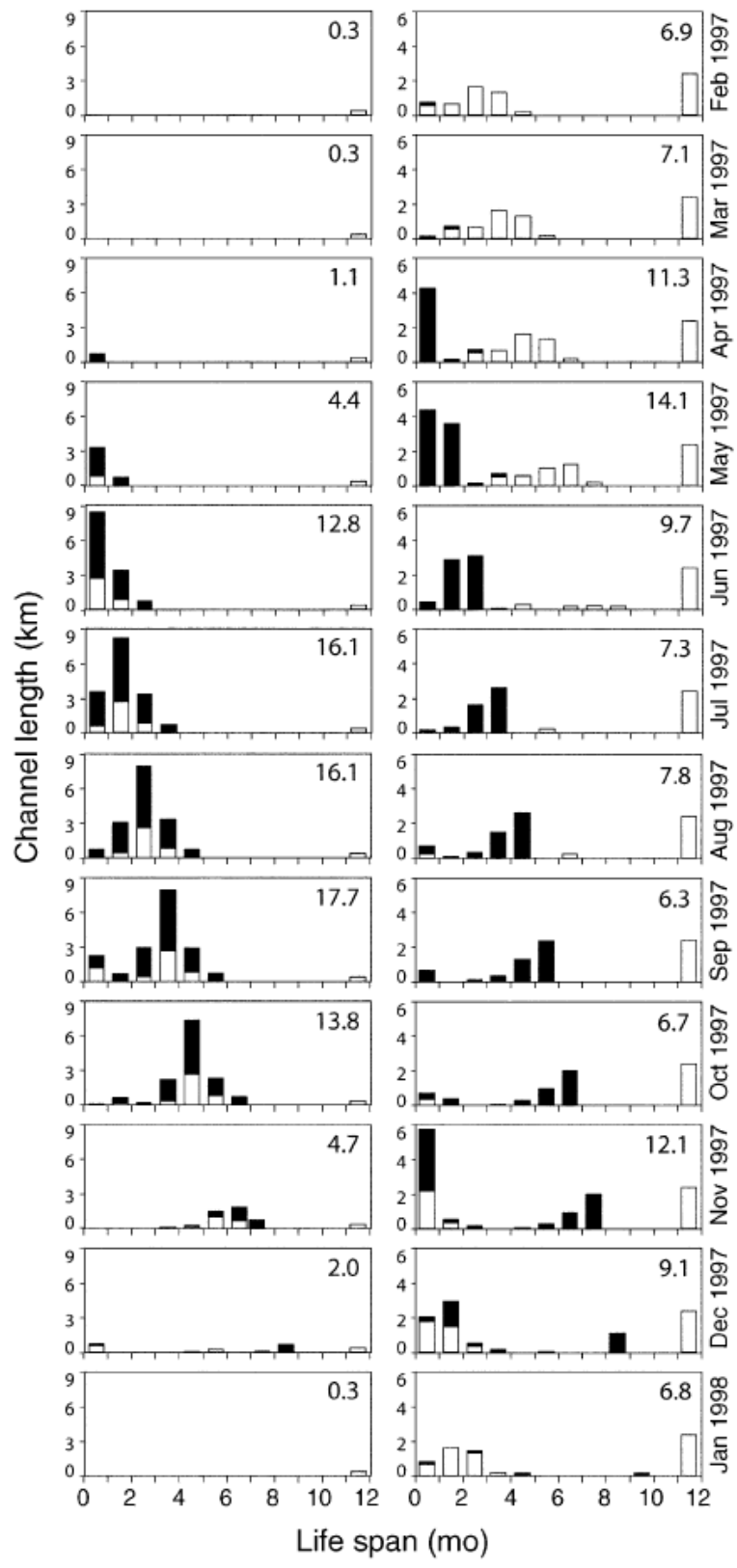

FIG. 4. Monthly changes in the life span distribution of turbid channels (left-hand panels) and clear channels (righthand panels) in 1997. Open parts of bars correspond to permanent channels and solid parts of bars to temporary channels. Numbers in the upper right corner of each panel indicate the length of channels $(\mathrm{km})$.

temporary clear habitats (III). The density of Chironomidae increased from June to November in clear habitats I and III (ANOVA, time effect, $P=0.003$ ). Oligochaeta were significantly more abundant in permanent clear habitats (I) than in other habitats (Tukey tests, $P<0.05$ ) but there were no differences in density between temporary groundwater habitats (III) and glacial water habitats (II, IV, and V).

\section{DiscusSION}

Expansion-contraction cycle

Natural riverscapes alternatively expand and contract over multiple temporal scales (Stanley et al. 1997). At the annual scale, the channel network in the Roseg River varied three- to fivefold in length (i.e., from 7.1 to $24 \mathrm{~km}$ and from 5.1 to $26.7 \mathrm{~km}$ in 1997 and 1999, respectively). Although not documented in this study, the size of the riverscape changed at a daily scale in summer and in response to unpredictable rainfall-induced spates. Zah et al. (2001) demonstrated that the area of the braided band has continuously increased over the last 50 years, probably in response to higher sediment availability and transport caused by the retreat of the glaciers (Ward and Uehlinger 2003). Because the Val Roseg is a high-gradient, deep, braided, gravelbed river with well-defined thalwegs, water flow was mostly confined to stream channels during the annual expansion-contraction cycle (Uehlinger et al. 2003). Only at river discharge exceeding $25 \mathrm{~m}^{3} / \mathrm{s}$ did water spill over the main channel banks to inundate a relatively small area of the braided band (i.e., a 30-60 m wide inundated corridor; Uehlinger et al. 2003). Fenn and Gurnell (1987) showed that the Tsidjiore Nouve proglacial stream, Switzerland, shifted from a single channel to multiple braids as it progressively reoccupied dry channels during the ice-melt season (a process known as secondary anastomosis). In contrast, Van der Nat et al. (2002) showed that the complete inundation of the braided band of the Tagliamento River, Italy, occurred three to four times per year. Mosley (1983) emphasized variations in flooded areas as a function of discharge among braided rivers of New Zealand and concluded that it was not feasible to predict changes in the channel character of braided rivers in response to discharge variation. The seasonal expansion of the Roseg riverscape was caused ultimately by an increased flux of snow and ice-melt water, however, melting water moved throughout the braided plain via surface and subsurface pathways (Malard et al. 1999). The simultaneous occurrence of two hydrological pathways maintained the complex mosaic of clear and turbid channels throughout the expansion phase.

\section{Riverscape composition and configuration}

Detailed analysis of the shifting mosaic of clear and turbid channels supported our first hypothesis: the hydrological processes involved in the expansion-contraction cycle resulted in a predictable trend of change in the composition and configuration of the riverscape as discharge increased and declined. We quantified a pattern that was expected from concepts in glacial river hydrology (Röthlisberger and Lang 1987), but we acknowledged that the exact proportion and location of clear and turbid channels remained difficult to predict because of local geomorphic and hydrologic processes. Whereas increased subsurface expansion of snow and 
TABLE 1. Characteristics of habitat types on the Roseg River.

\begin{tabular}{lccccc}
\hline \hline & \multicolumn{5}{c}{ Habitat types $\dagger$} \\
\cline { 2 - 6 } Characteristic & I & II & III & IV & V \\
\hline Life span (mo) $\$$ & & & & & \\
1997 & 12.0 & 12.0 & $7.2 \pm 1.5$ & $6.9 \pm 2.0$ & $5.6 \pm 2.3$ \\
1999 & 12.0 & 12.0 & $7.7 \pm 1.0$ & $6.6 \pm 1.9$ & $4.4 \pm 2.2$ \\
Duration of clear & & & & \\
$\quad$ water flo (mo)§ & & & & \\
1997 & 12.0 & $6.4 \pm 1.2$ & $7.2 \pm 1.6$ & $2.6 \pm 1.8$ & 0.0 \\
1999 & 12.0 & $6.0 \pm 1.6$ & $1.4 \pm 1.1$ & $2.9 \pm 1.7$ & 0.0 \\
Length (m) & & & & & \\
1997 & 2382 & 4315 & 4352 & 6140 & 7550 \\
1999 & 1425 & 3781 & 3354 & 10596 & 11923 \\
Percentage of total & & & & & \\
1997 & 9.6 & 17.4 & 17.6 & 24.8 & 30.5 \\
1999 & 4.6 & 12.2 & 10.8 & 34.1 & 38.4 \\
\hline
\end{tabular}

Note Error measurements shown are SD.

$\dagger$ Habitat types: I, permanent habitats fed exclusively by clear water; II, permanent habitats fed by clear water in winter and by turbid water during the ice-melt season; III, temporary habitats fed exclusively by clear water; IV, temporary habitats fed by clear water in spring and/or autumn and by turbid water in summer; and V, temporary habitats fed exclusively by turbid water.

tChannel segments belonging to permanent habitat types I and II all have a life span of 12 months; thus, their standard deviation is zero.

$\S$ Channel segments belonging to habitat types I and V all have a duration of clear water flo of 12 and 0 months, respectively. Thus, their standard deviation is zero.

ice-melt waters (via hillslope and alluvial aquifers) firs generated new clear channels in the upper braided band, the increased glacial surface water runoff then led to the floodin of dry channels and pre-existing clear channels with turbid water. This dual floodin process resulted in an almost complete change in the proportion of clear and turbid channels and spatial arrangement of clear channels within a short time $(<2 \mathrm{mo})$. The recession sequence began with a reduction in surface glacial water that resulted in a decrease in the extent of turbid channels and a concomitant increase in the extent of clear channels. Clear channels then progressively decreased as the recharge of hillslope and alluvial aquifers ceased. In their qualitative floodplai inundation model, Lewin and Hughes (1980) emphasized that distinct water sources and hydrological processes operated in a specifi order as discharge rose and receded. Mertes (1997) demonstrated, using remote-sensing and fiel data from several reaches of large rivers around the world, that the early fillin of floodplain with clear local water restricted the lateral expansion of turbid river water.

Differences in discharge between the years 1997 and 1999, and the occurrence of several rainfall-induced spates, including one with a recurrence interval of 50 years (peak discharge of $63 \mathrm{~m}^{3} / \mathrm{s}$ on 20 September 1999), did not modify the seasonal sequence of clear and turbid channel replacement. Although there were noticeable changes in the respective proportions of the fiv habitat types between 1997 and 1999, the composition and spatial configuratio of the riverscape was more stable than predicted earlier by Malard et al.
(2000:693). However, these results conform to more recent finding by Zah et al. (2001) who demonstrated that the structure of the channel network (i.e., sinuosity and braiding indexes) remained relatively constant over the last 50 years. They are also consistent with longterm observations of channel change in other upland braided rivers (Warburton et al. 1993, Fenn and Gurnell 1987). The braiding pattern of the Roseg River probably reflect the occurrence of prior channels with high contemporaneous flow insufficien to override their imprint in the morphology of the braided band (Warburton et al. 1993). Interannual morphological changes involve local erosion or deposition in the main channel leading to localized changes in the distribution of glacial flo within the braided band. For contrast, Van der Nat et al. (2003) measured a relative spatial change of aquatic habitats of $86 \%$ over a period of only 2.5 $\mathrm{yr}$ in a bar-braided reach of the Tagliamento River, Italian Alps. Because scouring spates reconfigure the spatial arrangement of aquatic habitats without modifying their relative proportion within the riverscape, Van der Nat et al. (2003) concluded that the dynamics of the braided band of the Tagliamento River conformed to the shifting mosaic steady-state model proposed by Borman and Likens (1979; see also Arscott et al. 2002). Longer periods of study are required to test whether this type of dynamic equilibrium also applies to the Roseg riverscape in response to the lateral movement of the main channel.

\section{Age distribution of clear and turbid water channels}

Flow variation in river systems not only controls the duration of the aquatic phase, but also the timing when 


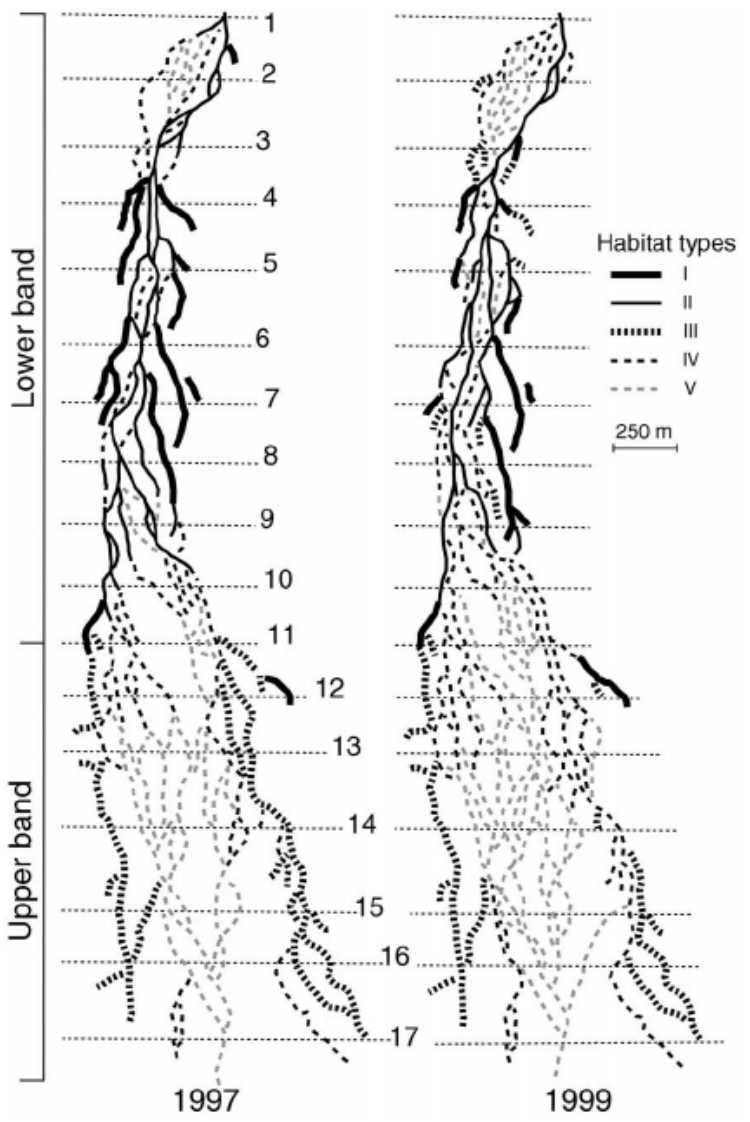

FIG. 5. Simplified maps of the braided band showing the distribution of five habitat types in 1997 and 1999. Habitat types are described in Table 1 .

channels are fed by distinct water sources. In addition to drying, changes in the physical environment (e.g., flow velocity, temperature) and in resource availability (e.g., periphyton biomass) caused by a shift in water source also can be considered a disturbance (sensu White and Pickett 1985). Burgherr et al. (2002) showed that the density and composition of zoobenthic assemblages in braided channels fluctuated drastically in response to changes in the relative contribution of glacial water to surface flow. In the Roseg River, surface flow was permanent in about $20 \%$ of the channel network and persisted on average $6 \mathrm{mo}$ in the remaining temporary channels. However, the average time a flowing channel remained continuously fed either by clear or turbid water was only 4.4 mo (excluding the permanent groundwater-fed channels that represented $<10 \%$ of the riverscape). Interestingly, the results showed that channels fed by distinct water sources could be viewed as cohorts that appeared, maintained, and disappeared during particular phases of the expansion-contraction cycle. As expected, the successive expansion and recession of glacial water resulted in a single cohort of turbid channels. In contrast, clear channels had a summer cohort and a winter cohort that appeared during the expansion and contraction phases of the riverscape, respectively. These two cohorts may either be used by invertebrate species with dissimilar life cycles or by the same species at different stages of its life cycle. Van der Nat et al. (2003) demonstrated that the halflife of aquatic habitats in braided reaches of the Tagliamento River was less than $7 \mathrm{mo}$. They suggested that the short time span of most habitats constrained species with long life cycles.

\section{Ecological effects of riverscape dynamics}

The extremely dynamic nature of natural riverscapes provides ideal settings to examine the consequences of changes in system size and spatial pattern on ecological processes and biodiversity. Change in aquatic habitat size is a fundamental feature of river systems that potentially affects all aspects of the ecosystem (Stanley et al. 1997, Benke 2000, Tockner et al. 2000). Despite the widespread occurrence of glacial river shrinkage during flow recession, almost no studies have considered that the autumnal increase in local zoobenthic density might reflect the concentration of individuals in the shrinking aquatic habitat (but see Burgherr et al. 2002). Distinct seasonal shifts in the density of zoobenthos were previously attributed to variation in temperature, channel stability, and food resources (Milner et al. 2001). In the Roseg River, the strong relationship between local zoobenthic density and total aquatic area strongly suggested that dilution-concentration effects were in part responsible for seasonal variations in the density of benthic invertebrates in the main channel. Previous studies of glacial rivers which ignored the effect of changing stream size might have attributed a disproportionate importance to ecological factors for explaining density variations.

Bed sediment movement is a primary factor limiting periphyton biomass in gravel-bed rivers (Biggs et al. $1999,2001)$. In glacial rivers, the growth of algae is

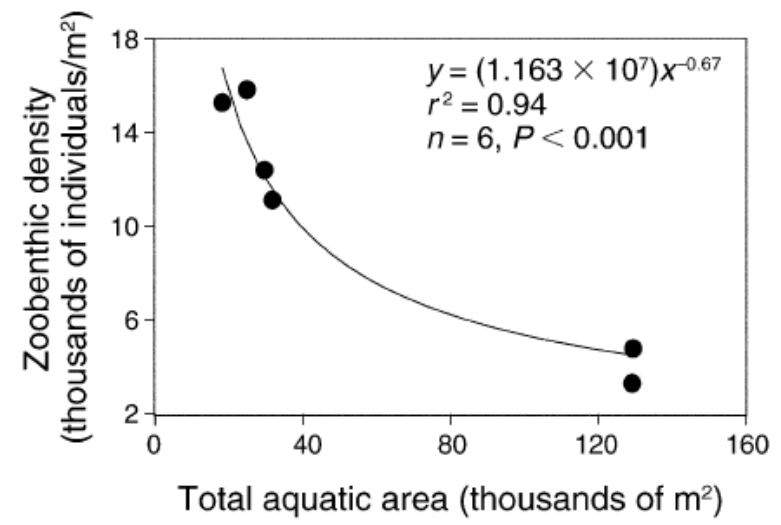

FIG. 6. Relationship between zoobenthic density at a main channel site (transect 6 in Fig. 1) and total aquatic area (data from Burgherr et al. [2002]). Zoobenthos were collected in April, June, August, October, November, and December 1997 $(n=3$ replicate samples per date). 

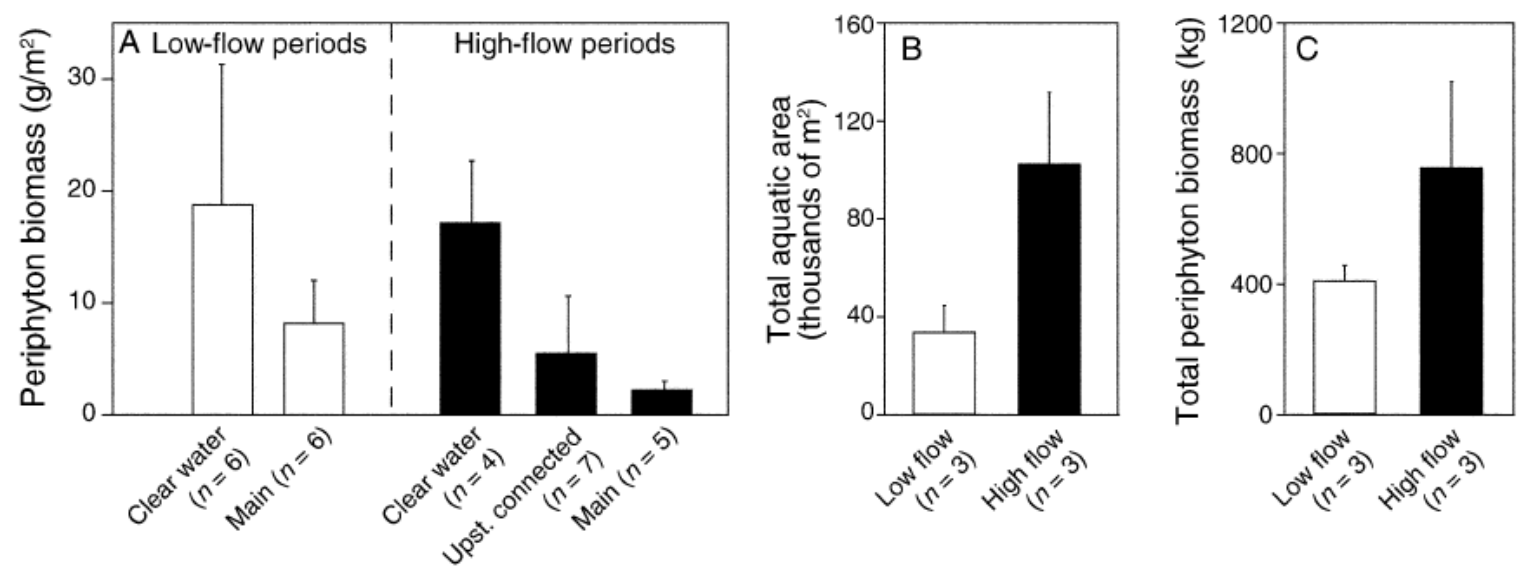

FIG. 7. (A) Characteristic pattern of periphyton biomass (ash-free dry mass, AFDM) among channel types (clear-water, main, and upstream connected) during low-flow (open bars) and high-flow (black bars) periods (data from Uehlinger and Zah [2003] for 15 December and 1 September 1997, respectively). (B, C) Differences in total aquatic area and total estimated biomass (AFDM) of epilithic algae in the braided band between periods of low flow (data from 15 April, 10 November, and 15 December 1997) and high flow (data from 5 August and 1 and 29 September 1997). Error bars show SD.

further constrained by light limitation due to high turbidity and by low supply of growth-limiting nutrients (Lloyd et al. 1987, Bürgi et al. 2003). During highflow periods, the combining effect of bed instability, reduced light availability, and low temperature severely limited the accrual of benthic algae in the main channel and upstream connected channels fed by glacial water. The rising proportion of these low-productivity habitats in the braided band mitigated the beneficial effect of the summer increase in aquatic habitat size on the total biomass of epilithic algae. The disproportionate increase in the proportion of unfavorable habitats during flooding presumably prevents braided rivers from sustaining high standing crops of algae and invertebrates (Tockner et al., in press). The moderate increase in algal biomass caused by the shift in riverscape composition might also restrict secondary production in the Roseg River. Rempel et al. (2000) suggested that high turbidity and fine sediment deposition in the Fraser River, Canada, limited algal and grazer productivity and accounted for the low representation of grazers in the zoobenthos. Mosley (1983) examined changes in the aquatic area usable by fishes as a function of discharge in several New Zealand braided rivers. The weighted usable area index (a function of water depth, flow velocity, and species preference) generally increased with river discharge but there were large differences in the shape of the relationship among rivers.

From a landscape perspective, biodiversity patterns in streams reflect the differential responses of organisms with distinct biological traits to the composition and spatial configuration of the riverscape (Townsend and Hildrew 1994, Wiens 2002). However, most predictive models of invertebrate community structure in streams including the disturbance-productivity-diver-
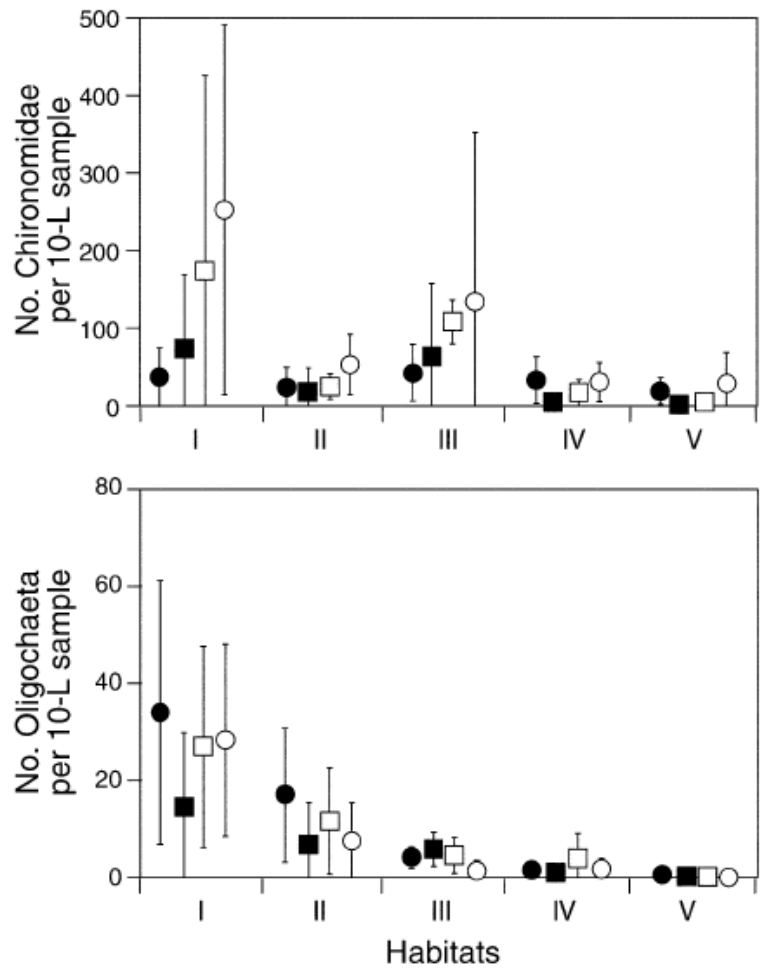

FIG. 8. Differences in hyporheic density of Chironomidae and Oligochaeta among habitats (see Table 1 and Fig. 5 for the definition of habitats). Solid circles, solid squares, open squares, and open circles correspond to sampling surveys carried out in June, August, September, and November 1997, respectively $(3 \leq n \leq 7$ replicate samples per habitat and date). Data are from Malard et al. (2003). Error bars represent SD. 
sity model (Hildrew and Townsend 1987) and the habitat templet model (Townsend and Hildrew 1994) largely ignored the ecological significanc of the spatial arrangement of habitats. Most invertebrates in this harsh braided riverscape are expected to preferentially select suitable clear water habitats (I and III) because they provide flo refugia with high substrate stability and high algal productivity during the summer expansion of glacial water. Flow refugia strongly contribute to the diversity of invertebrate communities in unstable graved-bed rivers although they often represent a small proportion of the total aquatic area (Rempel et al. 2000, Biggs et al. 2001; Tockner et al., in press). Temporary clear water habitats (III) may however be inaccessible flo refugia to species with poor dispersal capacities, because they are separated from permanent source areas of colonizers (I) by inhospitable glacial-fed channels (II, IV, and V). Differences in the spatiotemporal pattern of Chironomidae and Oligochaeta in shallow hyporheic sediments of the braided band support this hypothesis. Because of their high dispersal capacities (Robinson et al. 2004), chironomids equally colonized habitats I and III. Oligochaetes were abundant in permanent clear-water habitats (I) but they failed to colonize temporary clear-water habitats (III) in great numbers despite suitable environmental conditions and long flo duration ( 7 mo in habitat III). High flo velocity and bed instability in glacial-fed channels impeded the dispersal of oligochaetes via upstream migration (Malard et al. 2001). Vertical migration from groundwater was also severely limited by the weakness of hydrological connections between groundwater and hyporheic sediments in the upper braided band (Malard et al. 2003). Biodiversity patterns in expanding-contracting aquatic systems may not only reflec the spatial heterogeneity of environmental conditions but also the constraints imposed by the riverscape configuratio on the dispersal of organisms.

\section{CONCLUSIONS}

Landscape ecology is being recognized as a promising approach for developing a truly holistic perspective of river structure and function (Fisher et al. 2001, Ward et al. 2002; Stanford et al., in press). Conversely, riverscapes provide excellent arenas for testing landscape ecological theory (Wiens 2002). Variation in the flu of distinct water sources and hydrological pathways in a catchment makes riverscapes extremely dynamic over multiple temporal scales. In this braided glacial river, seasonal variation in the flu of melting water and surface and subsurface flo paths resulted in a predictable pattern in riverscape composition and configuration This seasonal pattern and resulting diversity of habitats which recurred among years despite contrasting annual flo (but see also Zah et al. 2001) might facilitate the development of adaptations among invertebrates for exploiting the natural floo regime (Lytle and Poff 2004). Quantifying the dynamics of riverscapes among natural river systems differing in their hydrology is a critical step in understanding their functions and to restore regulated riverine corridors. A next important step is to obtain quantitative estimates for determining how temporal changes in the size, composition, and configuratio of riverscapes affect biodiversity and bioproduction of river systems.

\section{ACKNOWLEDGMENTS}

This research was partly supported by a grant from the Swiss National Science Foundation (SNF grant 21-49243.96). We are indebted to P. Burgherr, C. Dambone, B. Fasnacht, D. Ferreira, B. Klein, and C. Robinson for their most dedicated help with the fiel work. We thank C. Robinson and D. Bade for reviewing a former draft of this text as well as C. Hupp and three anonymous reviewers for their valuable critiques that improved the manuscript.

\section{Literature Cited}

Arscott, D. B., K. Tockner, D. Van der Nat, and J. V. Ward. 2002. Aquatic habitat dynamics along a braided alpine river ecosystem Tagliamento River, Northeast Italy. Ecosystems 5:802-814.

Benke, A. C. 2000. Importance of floo regime to invertebrate habitat in an unregulated river-floodplai ecosystem. Journal of the North American Benthological Society 20: 225-240

Benke, A. C., I. Chaubey, G. M. Ward, and E. L. Dunn. 2000. Flood-pulse dynamics of an unregulated river floodplai in the southeastern U.S. coastal plain. Ecology 81:27302741 .

Biggs, B. J. F., M. J. Duncan, A. M. Suren, and J. R. Holomuzki. 2001. The importance of bed sediment stability to benthic ecosystems of streams. Pages 423-449 in M. P. Mosley, editor. Gravel-bed rivers V. New Zealand Hydrological Society, Christchurch, New Zealand.

Biggs, B. J. F., R. A. Smith, and M. J. Duncan. 1999. Velocity and sediment disturbance of periphyton in headwater streams: biomass metabolism. Journal of the North American Benthological Society 18:222-241.

Borman, F. H., and G. E. Likens. 1979. Pattern and process in a forested ecosystem. Springer-Verlag, New York, New York, USA.

Bou, C., and R. Rouch. 1967. Un nouveau champ de recherche sur la faune aquatique souterraine. Compte Rendus de l'Académie des Sciences de Paris 265:369-370.

Brown, L. E., D. M. Hannah, and A. M. Milner. 2003. Alpine stream habitat classification an alternative approach incorporating the role of dynamic water source contributions. Arctic, Antarctic, and Alpine Research 35:313-322.

Burgherr, P. 2000. Spatio-temporal community patterns of lotic zoobenthos across habitat gradients in an alpine glacial stream ecosystem. Dissertation No. 13829. Swiss Federal Institute of Technology, Zürich, Switzerland.

Burgherr, P., J. V. Ward, and C. T. Robinson. 2002. Seasonal variation in zoobenthos across habitat gradients in an alpine glacial floodplai Val Roseg, Swiss Alps. Journal of the North American Benthological Society 21:561-575.

Bürgi, H. R., P. Burgherr, and U. Uehlinger. 2003. Aquatic flora Pages 139-151 in J. V. Ward and U. Uehlinger, editors. Ecology of a glacial floo plain. Kluwer Academic Publishers, Dordrecht, The Netherlands.

Clesceri, L. S., A. E. Greenberg, and A. D. Eaton. 1998. Standard methods for the examination of water and wastewater. Twentieth edition. American Public Health Association, American Waterworks Association, Water Environment Federation, Washington, D.C., USA. 
ESRI. 1994. ARC commands. Environmental Systems Research Institute, Redlands, California, USA.

Fausch, K. D., C. E. Torgersen, C. V. Baxter, and H. W. Li. 2002. Landscapes to riverscapes: bridging the gap between research and conservation of stream fishes BioScience 52: 483-498.

Fenn, C. R., and A. M. Gurnell. 1987. Proglacial channel processes. Pages 423-472 in A. M. Gurnell and M. J. Clark, editors. Glacio-fluvia sediment transfer. Wiley, Chichester, UK.

Fisher, S. G., J. Welter, J. Schade, and J. Henry. 2001. Landscape challenges to ecosystem thinking: creative floo and drought in the American Southwest. Scientia Marina 65: 181-192.

Graham, A. A., D. J. S. McCaughan, and F. S. McKee. 1988. Measurement of surface area of stone. Hydrobiologia 157: $85-88$.

Hildrew, A. G., and C. R. Townsend. 1987. Organization in freshwater benthic communities. Pages $347-371$ in J. H. R. Gee and P. S. Giller, editors. Organization of communities past and present. Blackwell Scientifi Publications, Oxford, UK.

Junk, W. J., P. B. Bayley, and R. E. Sparks. 1989. The floo pulse concept in river-floodplai systems. Canadian Special Publication of Fisheries and Aquatic Sciences 106:110127.

Lesack, F. W., and J. M. Melack. 1995. Flooding hydrology and mixture dynamics of lake water derived from multiple sources in an Amazon floodplai lake. Water Resources Research 31:329-345.

Lewin, J., and D. A. Hughes. 1980. Welsh floodplai studies, II. Application of a qualitative inundation model. Journal of Hydrology 46:35-49.

Lloyd, D. S., J. P. Koenings, and J. D. LaPerriere. 1987. Effects of turbidity in fresh waters of Alaska. North American Journal of Fisheries Management 7:18-33.

Lytle, D. A., and N. L. Poff. 2004. Adaptation to natural flo regimes. Trends in Ecology and Evolution 19:94-100.

Malard, F., D. Ferreira, S. Dolédec, and J. V. Ward. 2003. Influenc of groundwater upwelling on the distribution of the hyporheos in a headwater river floo plain. Archiv für Hydrobiologie 157:89-116.

Malard, F., M. Lafont, M. Burgherr, and J. V. Ward. 2001. A comparison of longitudinal patterns in hyporheic and benthic oligochaete assemblages in a glacial river. Arctic, Antarctic, and Alpine Research 33:457-466.

Malard, F., K. Tockner, and J. V. Ward. 1999. Shifting dominance of subcatchment water sources and flo paths in a glacial floodplain Val Roseg, Switzerland. Arctic, Antarctic and Alpine Research 31:135-150.

Malard, F., K. Tockner, and J. V. Ward. 2000. Physico-chemical heterogeneity in a glacial riverscape. Landscape Ecology 15:679-695.

Mertes, L. A. K. 1997. Documentation and significanc of the perirheic zone on inundated floodplains Water Resources Research 33:1749-1762.

Milner, A. M., J. E. Brittain, E. Castella, and G. E. Petts. 2001. Trends of macroinvertebrate community structure in glacier-fed rivers in relation to environmental conditions: a synthesis. Freshwater Biology 46:1833-1847.

Mosley, M. P. 1983. Response of braided rivers to changing discharge. Journal of Hydrology 22:18-66.

Rempel, L. L., J. S. Richardson, and M. C. Healey. 2000. Macroinvertebrate community structure along gradients of hydraulic and sedimentary conditions in a large gravel-bed river. Freshwater Biology 45:57-73.
Robinson, C. T., M. O. Gessner, K. A. Callies, C. Jolidon, and J. V. Ward. 2000. Larch needle breakdown in contrasting streams of an alpine glacial floodplain Journal of the North American Benthological Society 19:250-262.

Robinson, C. T., K. Tockner, and P. Burgherr. 2004. Drift benthos relationships in the seasonal colonization dynamics of alpine streams. Archiv für Hydrobiologie 160:447-470.

Robinson, C. T., K. Tockner, and J. V. Ward. 2002. The fauna of dynamic riverine landscapes. Freshwater Biology 47: 661-677.

Röthlisberger, H., and H. Lang. 1987. Glacial hydrology. Pages 207-284 in A. M. Gurnell and M. J. Clark, editors. Glacio-fluvia sediment transfer. John Wiley and Sons, Chichester, UK.

Stanford, J. A., M. S. Lorang, and F. R. Hauer. In press. The shifting mosaic of river ecosystems. Verhandlungen der Internationalen Vereinigung für Theoretische und Angewandte Limnologie 29.

Stanley, E. H., S. G. Fisher, and N. B. Grimm. 1997. Ecosystem expansion and contraction in streams. BioScience 47:427-435.

Tockner, K., F. Malard, U. Uehlinger, and J. V. Ward. 2002. Nutrients and organic matter in a glacial river floodplai system Val Roseg, Switzerland. Limnology and Oceanography 47:266-277.

Tockner, K., F. Malard, and J. V. Ward. 2000. An extension of the floo pulse concept. Hydrological Processes 14: 2861-2883.

Tockner, K., A. Paetzold, U. Karaus, C. Claret, and J. Zettel. In press. Ecology of braided rivers. In G. H. Sambroock Smith, J. L. Best, C. S. Bristow, and G. Petts, editors. Braided rivers. IAS Special Publication. Blackwell, Oxford, UK.

Townsend, C. R., and A. G. Hildrew. 1994. Species traits in relation to a habitat templet for river systems. Freshwater Biology 31:265-275.

Uehlinger, U., F. Malard, and J. V. Ward. 2003. Thermal patterns in the surface waters of a glacial river corridor Val Roseg, Switzerland. Freshwater Biology 48:284-300.

Uehlinger, U., and R. Zah. 2003. Organic matter dynamics. Pages 199-215 in J. V. Ward and U. Uehlinger, editors. Ecology of a glacial floo plain. Kluwer Academic Publishers, Dordrecht, The Netherlands.

Van der Nat, D., A. Schmidt, K. Tockner, P. J. Edwards, and J. V. Ward. 2002. Inundation dynamics in braided flood plains. Ecosystems 5:636-647.

Van der Nat, D., K. Tockner, P. J. Edwards, J. V. Ward, and A. M. Gurnell. 2003. Habitat change in braided floo plains Tagliamento, NE-Italy. Freshwater Biology 48:1799-1812.

Warburton, J., T. R. H. Davies, and M. G. Mandl. 1993. A meso-scale fiel investigation of channel change and flood plain characteristics in an upland braided gravel-bed river, New Zealand. Pages 241-255 in J. L. Best and C. S. Bristow, editors. Braided rivers. Special Publication No. 75. Geological Society, London, UK.

Ward, J. V. 1994. Ecology of alpine streams. Freshwater Biology 32:277-294.

Ward, J. V., F. Malard, and K. Tockner. 2002. Landscape ecology: a framework for integrating pattern and process in river corridors. Landscape Ecology 17:35-45.

Ward, J. V., and U. Uehlinger, editors. 2003. Ecology of a glacial floo plain. Kluwer Academic Publishers, Dordrecht, The Netherlands.

White, P. S., and S. T. A. Pickett. 1985. Natural disturbance and patch dynamics: an introduction. Pages $3-13$ in S. T. 
A. Pickett and P. S. White, editors. The ecology of natural disturbance and patch dynamics. Academic Press, New York, New York, USA.

Wiens, J. A. 2002. Riverine landscapes: taking landscape ecology into the water. Freshwater Biology 47:501-515.

Zah, R., M. Niederöst, H. Rinderspacher, U. Uehlinger, and J. V. Ward. 2001. Long-term dynamics of the channel net- work in a glacial floodplain Val Roseg, Switzerland. Arctic, Antarctic, and Alpine Research 33:440-446.

Zah, R., M. Niederöst, and U. Uehlinger. 2000. Application of photogrammetry in freshwater ecology: analysing the morphology of a high Alpine floodplain International Archives of Photogrammetry and Remote Sensing 33:17391746 .

\section{APPENDIX A}

A photo of the lower braided band of the Roseg River (length, $1.6 \mathrm{~km})$ (Ecological Archives E087-041-A1).

\section{APPENDIX B}

A table providing compositional and configurationa characteristics of the riverscape (Ecological Archives E087-041-A2).

\section{APPENDIX C}

A figur showing the totality of the expansion-contraction cycle in 1997 and 1999 (Ecological Archives E087-041-A3).

\section{APPENDIX D}

A figur showing monthly changes in the age distribution of turbid channels and clear channels in 1999 (Ecological Archives E087-041-A4).

\section{APPENDIX E}

Detailed color maps showing the distribution of habitat types in 1997 and 1999 (Ecological Archives E087-041-A5). 